\title{
A Study of Sonographic Assessment of Gallbladder Dimensions in Normal Adults
}

\author{
Siva Prasad Chavva ${ }^{1}$, Santosh U Karpur ${ }^{2}$ \\ ${ }^{1}$ Associate Professor, ${ }^{2}$ Assistant Professor, Department of Radiology, Malla Reddy Institute of Medical Sciences, Hyderabad \\ - 500 055., Telangana, India
}

Corresponding author: Dr. Siva Prasad Chavva, Associate Professor, Department of Radiology, Malla Reddy Institute of Medical Sciences, Sy No. 138, Suraram Main Road, GHMC Quthbullapur Jeedimetla, Hyderabad - 500 055., Telangana, India

DOI: http://dx.doi.org/10.21276/ijcmsr.2018.3.4.35

How to cite this article: Siva Prasad Chavva, Santosh U Karpur. A study of sonographic assessment of gallbladder dimensions in normal adults. International Journal of Contemporary Medicine Surgery and Radiology. 2018;3(4):D157-D159.

\section{A B S T R A C T}

Introduction: Diseases of the gallbladder (GB) do affect its size and wall thickness. GB diseases are common pathology frequently encountered in medical practice and presents as right upper quadrant pain. Ultrasonography is a comparatively safe, inexpensive and reproducible tool for assessing normal or diseased gall bladder. There is inadequate data about normal gall bladder dimensions. Study objective was to deliver sonographic assessment of gall bladder dimensions in normal adults. Material and Methods: 300 healthy adult volunteers, involving 160 males and 140 females were selected and performed ultrasound, following overnight fasting. Gall bladder length, width, height and wall thickness were measured for these subjects. Gall Bladder volume was designed by the ellipsoid formula. Statistical significance among the variables was performed with the Students $t$-test, through ' $P$ ' value of $\leq 0.05$.

Results: The mean age of subjects was $31.92 \pm 11.7$ years. The mean values of the length $(L)$, height $(H)$, and width $(W)$ of the gall bladder were $6.19 \pm 1.09 \mathrm{~cm} ; 2.58 \pm 0.58 \mathrm{~cm}$; and $2.82 \pm 0.59 \mathrm{~cm}$, respectively. Mean gall bladder volume was $26.8 \pm 12.8$ $\mathrm{cm}^{3}$ and wall thickness $0.34 \pm 0.04 \mathrm{~cm}$. Age and gender did not show significant effect on gall bladder measurements.

Conclusion: A normal range of gall bladder dimensions for the Hyderabad has been documented. These values could be used as benchmark values in the treatment of gall bladder diseases.

Keywords: Gallbladder, Dimensions, Ultrasonography

\section{INTRODUCTION}

The gallbladder (GB) is a saccular structure situated in the GB fossa of the posterior right hepatic lobe. It is divided into fundus, body, infundibulum and neck. It has a pear or teardrop shape. Its main role is to store and concentrate bile for discharge into the duodenum for normal digestive process of fat. In normal individual bile flows from the GB into the cystic duct which is combined by the common hepatic duct to form the common bile ducts that open into the ampulla of Vater. $^{1}$ Numerous disease conditions that affect the hepatobiliary system could cause change in gall bladder-volume and wall thickness. Such conditions include choledocholithiasis, obstructive pancreatic lesions and others. There are various Imaging methods for assessing the gall bladder which include cholecystography, ultrasonography, computed axial tomography and magnetic resonance imaging. ${ }^{2,3}$ Though, ultrasonography (transabdominal) is the modality of choice because it is inexpensive, reproducible and does not use ionizing radiation.

Sonographically, the gall bladder is seen as a hollow organ, in the gall bladder fossa amongst the right and quadrate lobes of the liver. In para-sagittal scans, it lies between the liver and the kidney. It appears as a hollow viscous, with smooth margins and contains anechoic fluid that gives distal acoustic enhancement. The gall bladder wall, containing of the mucous, muscular and serous layers looks on ultrasound scan as a hyperechoic inner and outer layers and a less echogenic middle layer, particularly after contracted.

Numerous sonographic methods have been used to assess gall bladder volume, comprising two-dimensional ultrasonography, by the sum of cylinders and the ellipsoid method, as well as the three-dimensional ultrasonography. There are insufficient reports on sonographic valuation of gall bladder dimensions. ${ }^{4,5}$ Though no such data are available from the Hyderabad region. So this study was carried out to provide sonographic assessment of gall bladder dimensions in normal adults.

\section{MATERIAL AND METHODS}

This was a prospective study of gall bladder dimensions in 300 (Three hundred subjects ) apparently healthy adult volunteers, consisting of 160 males and 140 females. Subjects were the workers and students of the Malla Reddy Institute of medicalsciences, Hyderabad.

It was carried out at our radiology department between August 2015 - September 2016. Prior approval from the Institution Ethical Committee was obtained. Exclusion 
criteria comprised of age less than 18 years, diabetes, current history of jaundice, haemoglobinopathies, and past hepatobiliary surgery. Subjects on simultaneous medications like non-steroidal anti-inflammatory drugs, atropine and prostigmine, and those with accidental findings of gall bladder abnormalities during ultrasound scanning, were also excepted. Informed consent were obtained from all subjects. Biometric parameters comprising age, sex, height and weight were estimated.

Subsequent overnight fasting, ${ }^{6}$ the subjects were scanned using a digital real-time ultrasound system-model CTS7700, with a 3.5 MHz convex transducer. Every subject was asked to lie in supine position with the hands placed below the head to broaden the intercostal spaces. The gall bladder was scanned in relation to longitudinally and transversely. Measurements $(\mathrm{cm})$ in the maximum longitudinal and transverse axes of the gall bladder were obtained thrice and the mean for each was measured. The length (L) and wall thickness were measured in the longitudinal and axial planes, whereas the width (W) and height $(\mathrm{H})$ were obtained in the transverse section. The wall thickness was measured in every subject at the center of the gall bladder wall together to the liver. Gall bladder-volume was calculated by the ellipsoid formula (Figure 1).

\section{STATISTICAL ANALYSIS}

The data was entered into Microsoft Excel and was analyzed using Statistical Package for Social Science (SPSS) software for windows (SPSS Inc., USA) Version 15.0. The gall bladder dimensions and wall thickness were exposed to descriptive statistics by measuring the central tendency and dispersion and even this was related for age, sex, height, body mass index (BMI) and body surface area (BSA). Data comparison was performed by students $t$-test. $\mathrm{P} \leq 0.05$ was considered as statistically significant.

\section{RESULTS}

Three hundred healthy subjects consisting of 160 males (53.3\%) and 140 females (46.6\%) were studied. The age range of the subjects was $18-80$ years. The modal age group was $21-30$ years (77 males and 84 females), with the median age $31.92 \pm 11.7$ years.

The mean values of the length $(\mathrm{L})$, height $(\mathrm{H})$ and width $(\mathrm{H})$ of the gall bladder for the study population were $6.19 \pm 1.09$ $\mathrm{cm} ; 2.58 \mathrm{~cm} \pm 0.58 \mathrm{~cm}$ and $2.82 \pm 0.59 \mathrm{~cm}$ respectively. The mean gall bladder-volume and wall thickness was $26.8 \pm 12.8$ $\mathrm{cm}^{3}$ and $0.33 \pm 0.04 \mathrm{~cm}$ respectively.

Comparison between the mean gall bladder dimensions and wall thickness for males and females (using unpaired t test) showed no statistically significant difference for gall bladder

\begin{tabular}{|l|c|c|c|}
\hline & Female & Male & P value \\
\hline Length $(\mathrm{cm})$ & $6.09 \pm 18$ & $6.26 \pm 19$ & NS \\
\hline Height $(\mathrm{cm})$ & $2.60 \pm 0.23$ & $2.54 \pm 0.21$ & NS \\
\hline Width $(\mathrm{cm})$ & $2.96 \pm 0.34$ & $2.43 \pm 0.16$ & NS \\
\hline Volume $\left(\mathrm{cm}^{3}\right)$ & $25.56 \pm 2.4$ & $26.76 \pm 2.7$ & NS \\
\hline Wall thickness $(\mathrm{cm})$ & $0.35 \pm 0.43$ & $0.33 \pm 0.35$ & NS \\
\hline
\end{tabular}

Table-1: Comparison between the mean gall bladder dimensions and wall thickness for males and females

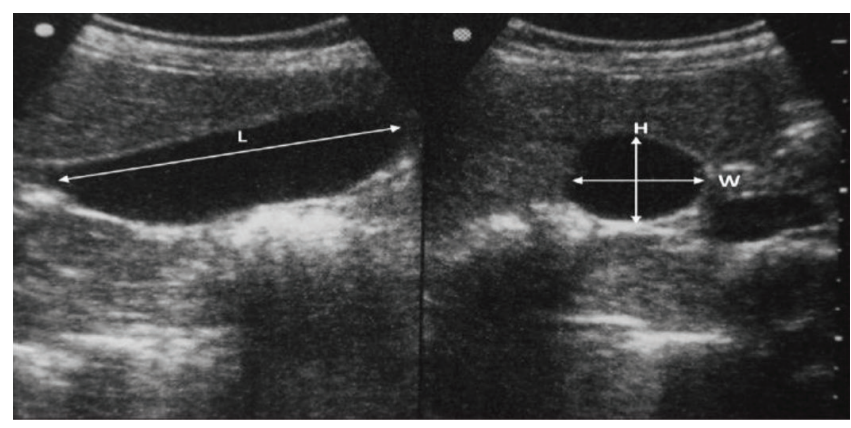

Figure-1: Shows longitudinal and transverse sonograms of fasting GALL BLADDER, and how maximum length (L), width $(\mathrm{W})$, and height $(\mathrm{H})$ were measured.

length, height, width, volume and wall thickness respectively [table 1].

Analysis of variance displayed no significant difference in gall bladder dimensions among the different age groups ( $P=0.097,0.843,0.950,0.342$ and 0.526$)$, for length, height, width, volume and wall thickness, respectively.

The gall bladder length, height, width, volume and wall thickness displayed no significant difference with the heights of subjects. However, there was statistically significant relationship between gall bladder height, width, and volume with subject body weights. Subjects with weight range 86-95 $\mathrm{kg}$ had the highest mean gall bladder volume of $32.43 \pm 15.95$ $\mathrm{cm}^{3}$. Gall bladder wall thickness and length had no significant relationship to body weight. Even BMI had no significant correlation to gall bladder length, height, width, and volume. BSA of subjects displayed significant association with all gall bladder dimensions $(P=0.01)$, except for length and wall thickness; $(P=0.904$ and 0.089$)$ respectively.

Correlation analysis showed significant correlation between the weight of subjects and gall bladder height and width $(P=0.01, r=0.1212 ; P=0.01, r=0.115)$. There was strong correlation between weight and gall bladder-volume.

No statistically significant relationship between the weights of subjects and gall bladder length, or wall thickness were observed.

\section{DISCUSSION}

Gall bladder size estimation is important in physiological states like pregnancy and pathological conditions like cholelithiasis, primary sclerosing cholangitis, primary biliary cirrhosis, and noninsulin-dependent diabetes mellitus and these conditions can increase the gall bladder volume. Also, a thick-walled GB is an evidence of gall bladder disease and considered symbol of acute cholecystitis. Though, this observation is not definite and could be found in additional diseases of the gall bladder and extracholecystic pathological diseases. ${ }^{1}$

This study presented a mean gall bladder-volume of $26.8 \pm 12.8 \mathrm{~cm}^{3}$; mean length of $6.19 \pm 1.09 \mathrm{~cm}$; and mean wall thickness of $0.33 \pm 0.04 \mathrm{~cm}$. Ugwu found a mean gall bladder-volume of $29.29 \pm 13.75 \mathrm{~cm}^{3}$. Probable cause might be lack of significant variation in gall bladder volume among Hyderabad population.

Earlier studies on gall bladder volume on normal, diabetic and pregnant subjects are available from various studies. ${ }^{8-13}$ Sari 
et al., ${ }^{9}$ and Kishk et al., ${ }^{12}$ have documented almost similar mean gall bladder-volume of $28.1 \pm 12.3 \mathrm{~cm}$ and $28.0 \pm 12.0$ $\mathrm{cm}$ respectively in normal subjects. This suggest that there is lack of significant racial variation in gall bladder-volume. Olokoba et al., ${ }^{4}$ considered the association between gallstone disease and gall bladder wall thickness and they have found that mean gall bladder thickness was $2.1 \pm 1.2 \mathrm{~mm}$; however our study showed a value of $0.34 \pm 0.4 \mathrm{~mm}$.

Gall bladder dimensions have been documented by studies varied with age, sex, weight, height, BMI and BSA..$^{8-12}$ Present study did not find a significant difference in gall bladder-volume among genders. Nieves et al., ${ }^{8}$ study also found that there is no effect of gender on gall bladder dimensions. Another study by Ngige et al., ${ }^{13}$ also accounted any effect of gender on gall bladder dimensions in children with sickle cell disease.

There was no impact of age on gall bladder dimensions in this study, conflicting with the finding of Caroli-Bose et al., that showed gall bladder volume was positively correlating with age. Also studies by Yoo et al., ${ }^{14}$ and by Ngige et al., ${ }^{13}$ had showed positive correlation between gall bladder-volume and age. It is significant to point that these studies were done among children population; so the cause for this could be due that most organs ascent to growth in size during the active growth phase.

This study showed weight and BSA positively correlated with the width, height and volume of the gall bladder. Yoo et al., ${ }^{14}$ and Sari et al., ${ }^{9}$ also showed a positive correlation between subject weight and gall bladder-volume among Asians.

Present study didn't display any relationship between BMI and gall bladder length, width, height and volume, hence it concurrent with the study done by Caroli-Bose et al. ${ }^{7}$ However another study by $\mathrm{Ugwu}^{3}$ in 2007 showed a relationship between BMI and gall bladder-volume. Previous study have demonstrated greater fasting gall bladder-volume in obese subjects than in non-obese controls. ${ }^{10} \mathrm{~A}$ possible justification for this could be that BMI doesn't differentiate between body fat mass and muscle mass, and that BMI might not truly reproduce body fat mass in this study population. By using correlation and regression analysis, there was no positive correlation between gall bladder wall thickness and the BMI.

The body surface area showed positive association with the width and volume of the gall bladder from this study, which agreed with the study performed by $\mathrm{Ugwu}^{3}$ in 2007 and also several other studies. ${ }^{10-15}$ Present study established that there is no significant difference in mean gall bladder-volume and wall thickness compared with other research works. The pattern of correlation between gall bladder-volume and demographic parameters, however, tend to vary among different studies.

\section{CONCLUSION}

This study established a normal range of gall bladder dimensions in asymptomatic adults in Hyderabad City. These values could be used as benchmark values in treatment of GB disease

\section{REFERENCES}

1. Stephanie R, Michelle M, Stephen E. Anatomy for
Diagnostic Imaging. 2nd ed. London; Elsevier: 2004. p. 178.

2. Berthold B. The Practice of Ultrasound: A Step to Step Guide to Abdominal Scanning. Stuttgart: George Thieme Verlag; 2004.p. 106-39.

3. Ugwu AC. Body surface area as a surrogate measure of gallbladder sizes and indices; a predictive equation in humans. Sudan JMS 2007;2(1):101-4.

4. Olokoba B, Bojuwoye BJ, Olokoba LB, Wahab KW, Braimoh KT, Inikori AK, et al. The relationship between gallstone disease and gallbladder wall thickness. Afr Sci 2006;7(3):171-6.

5. Sanders RC, Winter T. Clinical Sonography: A Practical Guide. 4 th ed. Philadelphia: Lippincott Williams and Wilkins; 2007. p. 81-93.

6. Dodds WJ, Groh WJ, Darweesh RM, Lawson TL, Kishk SM, Kern MK. Sonographic measurement of gallbladder volume. AJR Am J Roentgenol 1985;145(5):1009-11.

7. Caroli-Bosc FX, Pugliese P, Peten EP, Demarquay JF, Montet JC, Hastier P, et al. Gallbladder volume in adults and its relationship to age, sex, body mass index, body surface area and gallstones. An epidemiologic study in a nonselected population in France. Digestion 1999;60(6):344-8.

8. Nievolumees MA, Bueno J, Gaona Yánez C, Mercedes González M. Comparative study of gallbladder volume and contraction in healthy subjects of various ages and sex by ultrasonography. GEN 1989;43(4):13-7.

9. Sari R, Balci MK, Coban E, Karayalcin U. Sonographic evaluation of gallbladder volume and ejection fraction in obese women without gallstones. J Clin Ultrasound 2003;31(1):352-7.

10. Bravolumeerman DZ, Johnson ML, Kern F Jr. Effects of pregnancy and contraceptive steroids on gallbladder function. N Engl JMed 1980;302(3):362-4.

11. Agarwal AK, Miglani S, Singla S, Garg U, Dudeja RK, Goel A. Ultrasonographic evaluation of gallbladder volume in diabetics. J Assoc Physicians India 2004;52(5):962-5.

12. Kishk SM, Darweesh RM, Dodds WJ, Lawson TL, Stewart ET, Kern MK, et al. Sonographic evaluation of resting gallbladder volume and postprandial emptying in patients with gallstones. AJR Am J Roentgenol 1987;148(6):875-9.

13. Ngige EN, Renner JK, Temiye EO, Njokanma OF, Arogundade RA, David AN. Ultrasonographic measurement of the hepatobiliary axis of children with sickle cell anaemia in steady state. Niger J Clin Biomed Res 2006;1(2):44-50.

14. Yoo JH, Kwak HJ, Lee MJ, Suh JS, Rhee CS. Sonographic measurements of normal gallbladder sizes in children. J Clin Ultrasound 2003;31(9):80-4.

15. Gourtsoyiannis NC, Damilakis JE, Charoulakis NZ, Bakantaki AS, Vlahonikolis JG, Xynos E. Relationship of gallbladder contour, fasting volume and emptying to body size indices in normal subjects and patients with gallstones. Digestion

Source of Support: Nil; Conflict of Interest: None

Submitted: 05-08-2018; Accepted: 07-09-2018; Published online: 02-01-2019 